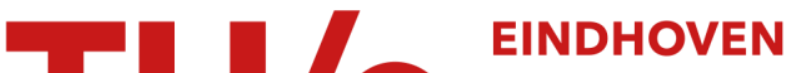

\section{Electromagnetic modelling of large complex 3-D structures with LEGO and the eigencurrent expansion method}

\section{Citation for published version (APA):}

Lancellotti, V., Hon, de, B. P., \& Tijhuis, A. G. (2009). Electromagnetic modelling of large complex 3-D structures with LEGO and the eigencurrent expansion method. In Proceedings IEEE Antennas and Propagation Society International Symposium, 2009, APSURSI '09, 1-5 June 2009, Charleston, SC (pp. 1-4). Institute of Electrical and Electronics Engineers. https://doi.org/10.1109/APS.2009.5172216

DOI:

10.1109/APS.2009.5172216

Document status and date:

Published: 01/01/2009

\section{Document Version:}

Publisher's PDF, also known as Version of Record (includes final page, issue and volume numbers)

\section{Please check the document version of this publication:}

- A submitted manuscript is the version of the article upon submission and before peer-review. There can be important differences between the submitted version and the official published version of record. People interested in the research are advised to contact the author for the final version of the publication, or visit the $\mathrm{DOI}$ to the publisher's website.

- The final author version and the galley proof are versions of the publication after peer review.

- The final published version features the final layout of the paper including the volume, issue and page numbers.

Link to publication

\section{General rights}

Copyright and moral rights for the publications made accessible in the public portal are retained by the authors and/or other copyright owners and it is a condition of accessing publications that users recognise and abide by the legal requirements associated with these rights.

- Users may download and print one copy of any publication from the public portal for the purpose of private study or research.

- You may not further distribute the material or use it for any profit-making activity or commercial gain

- You may freely distribute the URL identifying the publication in the public portal.

If the publication is distributed under the terms of Article 25fa of the Dutch Copyright Act, indicated by the "Taverne" license above, please follow below link for the End User Agreement:

www.tue.nl/taverne

Take down policy

If you believe that this document breaches copyright please contact us at:

openaccess@tue.nl

providing details and we will investigate your claim. 


\title{
Electromagnetic modelling of large complex 3-D structures with LEGO and the eigencurrent expansion method
}

\author{
Vito Lancellotti*, Bastian P. De Hon, and Anton G. Tijhuis \\ Department of Electrical Engineering, Eindhoven University of \\ Technology, P.O. Box 513, 5600 MB Eindhoven, The Netherlands \\ E-mail: v.lancellotti@tue.nl
}

\section{Introduction}

Linear embedding via Green's operators (LEGO) is a computational method in which the multiple scattering between adjacent objects — forming a large composite structure - is determined through the interaction of simple-shaped building domains, whose electromagnetic (EM) behavior is accounted for by means of scattering operators. This method has been successfully demonstrated for 2-D electromagnetic band-gaps (EBG) and other structures [1], and for very simple 3-D configurations [2]. In this communication we briefly report on the full extension of LEGO to large complex 3-D structures, which may be EBG-based but may also include finite antenna arrays as well as frequency selective surfaces, to name but a few applications. In particular, we shall outline two modifications that were crucial for scaling up the LEGO method, namely, the introduction of a total inverse scattering operator $\mathrm{S}^{-1}$ and the eigencurrent expansion method (EEM) [3].

In the LEGO concept (Fig. 1), we tackle the numerical solution to the EM problem by first characterizing an object or a set of objects - located within a bounded domain $\mathcal{D}_{1}$ - using a scattering operator $S_{11}$, which relates equivalent incident currents $q_{1}^{\mathrm{i}}$ (reproducing the incident field inside $\mathcal{D}_{1}$ ) to equivalent scattered currents $q_{1}^{\text {s }}$ (radiating the scattered field outside $\mathcal{D}_{1}$ ). $\mathrm{S}_{11}$ is an integral operator which can be obtained upon posing proper boundary integral equations on $\partial \mathcal{D}_{1}$ and the object surface. Subsequent application of the Method of Moments (MoM) - in conjunction with Rao-Wilton-Glisson (RWG) basis functions to expand the currents - yields $\left[S_{11}\right]$, the matrix (algebraic) counterpart of $S_{11}$. The next step, in principle, consists of combining the scattering operators of $N_{D}$ domains to obtain the (larger) operator $\mathrm{S}$ of the whole structure: we refer to this procedure as embedding [1]. To be specific, starting from, e.g., $S_{11}$ and $S_{22}$, a new operator, twice as big, may be built: then, we have to iterate this step as many times as necessary in order to characterize $N_{D}$ domains as a whole. Clearly, once $\mathrm{S}$ is known, the scattered currents simply ensue, with evident notation, through $q^{\mathrm{s}}=\mathrm{S} q^{\mathrm{i}}$, where $q^{\mathrm{i}}\left(q^{\mathrm{s}}\right)$ contains the incident (scattered) currents of all domains (see Eq. (1) below).

Although the strategy above was indeed followed for 2-D problems [1], we recognize that it is hardly viable for $3-\mathrm{D}$ ones. In fact, as the size of the new $[S]$ matrix doubles at each step, a naïve application of the embedding would soon drain the memory of most computers - which ultimately poses serious limitations to the number of domains that can be handled at the same time. In order to circumvent this drawback, we have combined LEGO with EEM applied to $\mathrm{S}^{-1}$, instead of $\mathrm{S}$. 


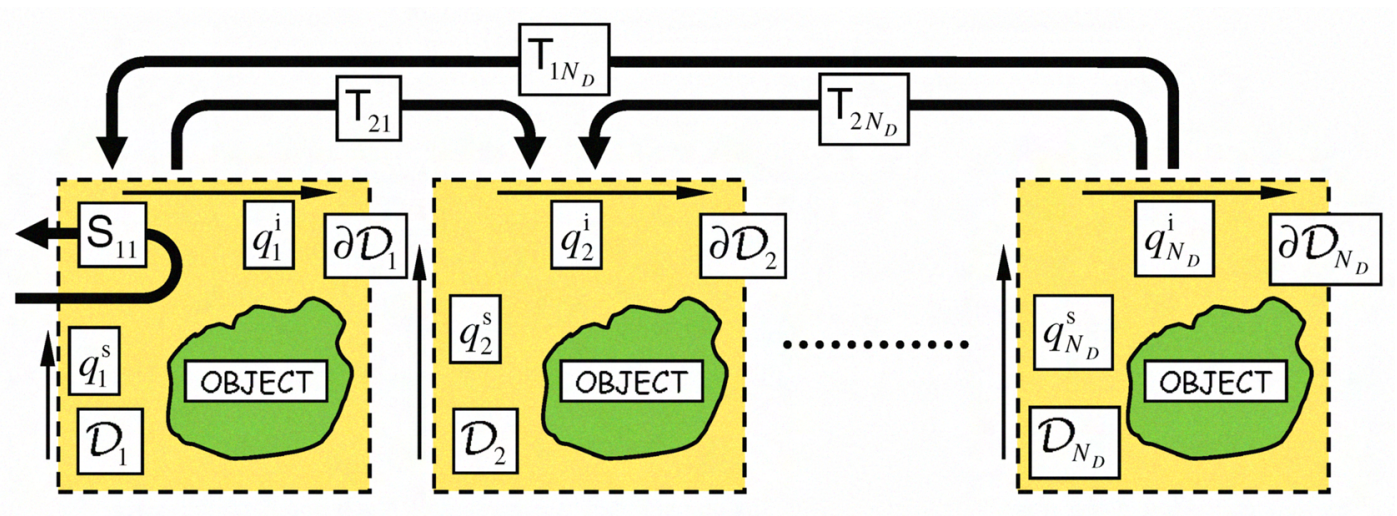

Figure 1: Modified LEGO concept: multiple scattering between adjacent objects is described by 1) defining elementary domains described via scattering operators and 2) building a total inverse scattering operator $S^{-1}$ which accounts for all the EM interactions.

\section{The operator $S^{-1}$ and the eigencurrent expansion method}

Since computing and storing the total $[S]$ turns out to be impracticable for large structures, we first observe that its inverse, $\mathrm{S}^{-1}$, may be written analytically in a formal fashion, in terms of $\mathrm{S}_{k k}^{-1}$ and transfer operators $\mathrm{T}_{k l}, k, l=1, \ldots, N_{D}$ (Fig. 1), where $\mathrm{T}_{k l}$ acts on $q_{l}^{\mathrm{s}}$ on $\partial \mathcal{D}_{l}$ to yield $q_{k}^{\mathrm{i}}$ on $\partial \mathcal{D}_{k}$. Thus, it appears more convenient to formulate the EM problem as an equation to be solved for $q^{\mathrm{s}}$, namely, $\mathrm{S}^{-1} q^{\mathrm{s}}=q^{\mathrm{i}}$, where

$$
\mathrm{S}^{-1}=\left[\begin{array}{cccc}
\mathrm{S}_{11}^{-1} & -\mathrm{T}_{12} & \cdots & -\mathrm{T}_{1 N_{D}} \\
-\mathrm{T}_{21} & \mathrm{~S}_{22}^{-1} & \cdots & -\mathrm{T}_{2 N_{D}} \\
\vdots & \vdots & \ddots & \vdots \\
-\mathrm{T}_{N_{D} 1} & -\mathrm{T}_{N_{D} 2} & \cdots & \mathrm{S}_{N_{D} N_{D}}^{-1}
\end{array}\right], q^{\mathrm{s}, \mathrm{i}}=\left[\begin{array}{c}
q_{1}^{\mathrm{s}, \mathrm{i}} \\
q_{2}^{\mathrm{s,i}} \\
\vdots \\
q_{N_{D}}^{\mathrm{s}, \mathrm{i}}
\end{array}\right], q_{k}^{\mathrm{s}, \mathrm{i}}=\left[\begin{array}{c}
\boldsymbol{J}^{\mathrm{s}, \mathrm{i}} \\
\boldsymbol{M}^{\mathrm{s}, \mathrm{i}}
\end{array}\right]
$$

To solve $\mathrm{S}^{-1} q^{\mathrm{s}}=q^{\mathrm{i}}$, however, we do not employ the MoM directly, for $[S]^{-1}$ could neither be stored nor inverted, but rather we use the MoM combined with the EEM. The very idea behind the EEM is to expand $q^{\text {s,i }}$ on a set of basis functions which are "approximations" to the eigenfunctions of $\mathrm{S}^{-1}$, say $s_{n}^{k}, n \in \mathbb{N}$.

To begin with, by applying the MoM with $N_{F}$ RWG basis functions per domain $\partial \mathcal{D}_{k}$, we determine the eigenvalues $\lambda_{k p}$ and eigenvectors $u_{p}^{k}, p=1, \ldots, N_{F}$, of $\left[S_{k k}\right]$. We note in passing that $u_{p}^{k}$ are dubbed eigencurrents, since they indeed exhibit the physical dimension of a current density, owing to the meaning of $\mathrm{S}_{k k}$. Then, we form a basis $E=\left\{e_{p}^{k}\right\}$ for $q^{s, i}$ upon juxtaposing $u_{p}^{k}$ : for instance, the element $e_{p}^{k}=\left[0, \ldots, 0, u_{p}^{k}, 0, \ldots, 0\right]^{t}$, i.e., it vanishes over all domain boundaries but the $k$ th. We still name $\left\{e_{p}^{k}\right\}$ eigencurrents, even though, apparently, they are not the true eigencurrents of $\mathrm{S}$. Besides, we speculate that only few elements of $E$, namely, those germane to the larger eigenvalues of each $\left[S_{k k}\right]$, will depart considerably from the corresponding $s_{n}^{k}$ : we say that these eigencurrents are coupled. Conversely, we expect most elements of $E$, viz., those relative to the higher order eigenvalues, to constitute increasingly better approximations to $s_{n}^{k}$. The latter may properly be termed uncoupled. 
In light of these observations, it appears advantageous to adopt $E$ to represent $q^{\text {s,i }}$, for we may stipulate, prior to filling $[S]^{-1}$, that not all of its entries are equally meaningful. More precisely, on the one hand the off-diagonal entries corresponding to the interaction between uncoupled or coupled/uncoupled eigencurrents must be relatively small and may be neglected altogether: in this instance, we are left with a diagonal inverse (partial) scattering operator $\left[S_{\mathrm{unc}}\right]^{-1}=\operatorname{diag}\left\{\lambda_{k p \text {, unc }}^{-1}\right\}$, the inversion of which is manifestly formal. On the other hand, the entries pertaining to the interaction of the coupled eigencurrents do matter and constitute a reduced inverse scattering operator $\left[S_{\text {red }}\right]^{-1}$, whose size is far smaller than that of the full $[S]^{-1}$, i.e., if we had used the original RWG functions distributed over all of the $N_{D}$ domains. Therefore, computing $q^{\text {s }}$ boils down to just filling and inverting $\left[S_{\text {red }}\right]^{-1}$ and eventually reverting to the pristine basis of RWG functions, also taking into account the uncoupled eigencurrents.

To give a clue as to the benefits gained in terms of memory, for a problem with $N_{D}$ domains and $N_{F}$ RWG functions per domain and $N_{\lambda}<<N_{F}$ coupled eigencurrents, the size of the system to be actually stored and inverted shrinks down to $N_{D} N_{\lambda} \times$ $N_{D} N_{\lambda}$ from a humongous $N_{D} N_{F} \times N_{D} N_{F}$. As a further advantage of the proposed approach, we cursorily point out that the construction of $[S]^{-1}$ relies on $\left[T_{k l}\right]$, the calculation of which involves just pairs of domains at a time (see Fig. 1). Since these calculations can obviously be carried out in parallel, it is seen that LEGO along with the inverse scattering operator intrinsically lends itself to parallelization. As a final remark, we emphasize that $[S]^{-1}$ is never built as such nor are its matrix elements $\left[S_{k k}\right]^{-1}$, for their eigencurrents and eigenvalues are computed through $\left[S_{k k}\right]$.

\section{Validation and results}

We have implemented LEGO and EEM in a numerical (parallel) code and to validate it we have considered, among others, two dielectric spheres (Fig. 2a) illuminated by a plane wave. Superimposed in Fig. $2 \mathrm{c}$ are the radar cross sections (RCS) obtained solving the EM problem directly $(-,--)$ with a PMCHW equation $(2 \times 2 \times 300$ RWG functions) and applying the LEGO/EEM concept $(\bullet)$ with $N_{F}=2 \times 900$ RWG functions on each cubic domain boundary and only $N_{\lambda}=10<<N_{F}$ coupled eigencurrents: it is seen that the two results are practically undistinguishable.

As an example of application, for an open defect cavity, made of 36 finite-length cylindrical holes in a homogeneous dielectric background and arranged in a hexagonal lattice (Fig. 2b), we have computed the RCS in response to a plane wave impinging from top (Fig. 2d). The number of RWG functions over each hexagonal domain boundary is $N_{F}=2 \times 756$, whence the total $[S]^{-1}$ would virtually be size $54432 \times 54432$, but upon using the EEM with only $N_{\lambda}=10$ coupled eigencurrents, we just handle $\left[S_{\text {red }}\right]^{-1}$ size $360 \times 360$.

\section{Acknowledgments}

This research has been financially supported by the post-doc fund under TU/e project no. 36/363450, and is performed in the framework of the MEMPHIS project. 
(a)

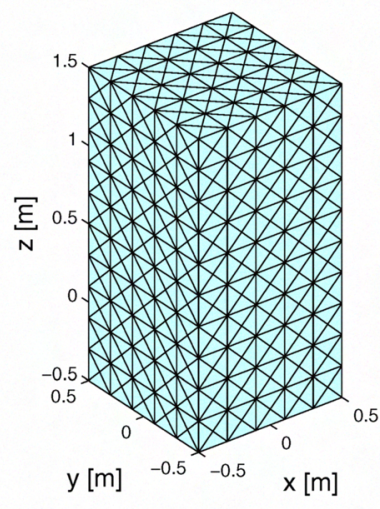

(c)

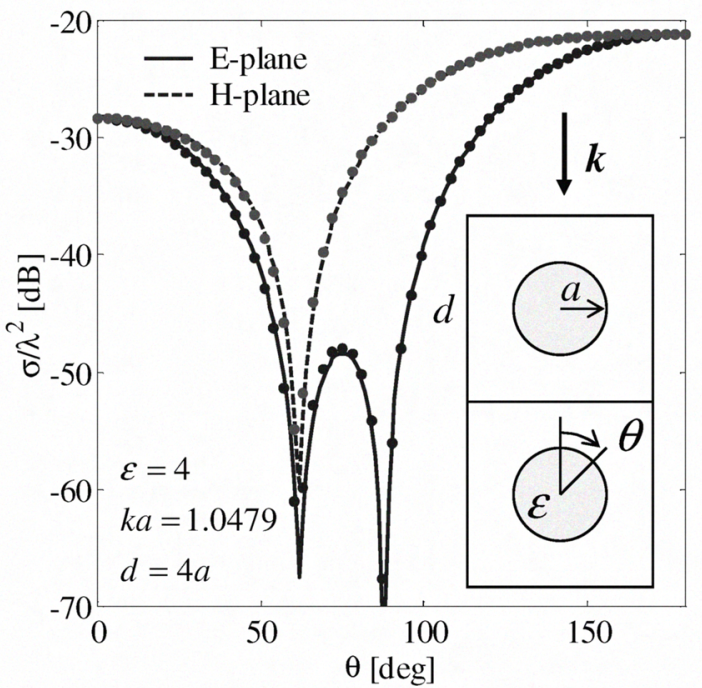

(b)

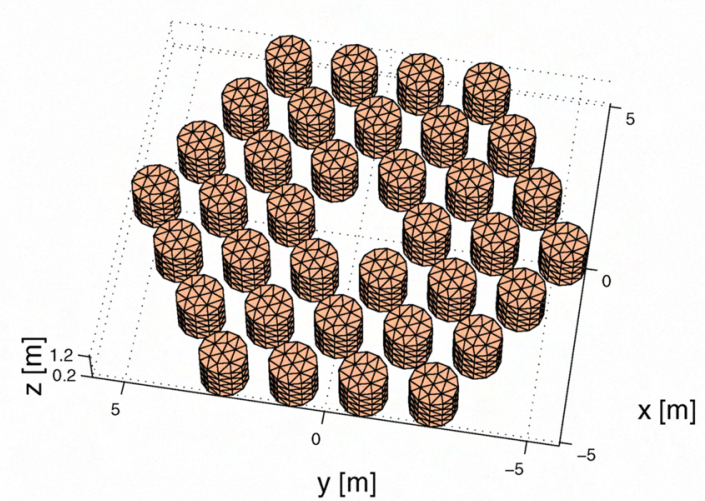

(d)

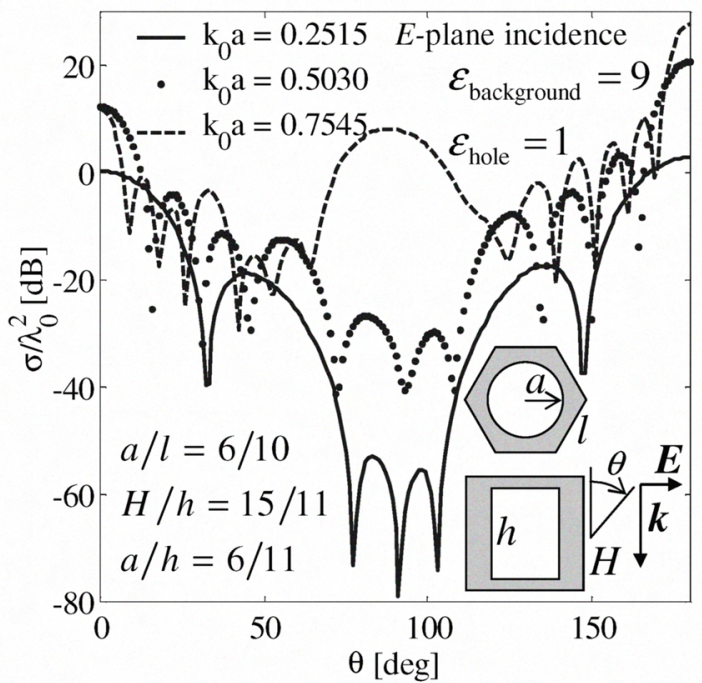

Figure 2: LEGO validation and results: (a) two cubic domains, which embed dielectric spheres, and triangular mesh; (b) 36-hole open defect cavity and triangular mesh (embedding hexagonal domains omitted for the sake of brevity); (c) RCS of the two dielectric spheres, $(\bullet)$ LEGO, (-,--) direct solution with PMCWH equation; (d) RCS of the open defect cavity.

\section{References}

[1] A. M. van de Water, B. P. de Hon, M. C. van Beurden, A. G. Tijhuis, and P. de Maagt, "Linear embedding via Green's operators: A modeling technique for finite electromagnetic band-gap structures," Phys. Re. E, vol. 72, pp. 1-11, 2005.

[2] A. M. van de Water, B. P. de Hon, A. G. Tijhuis, and M. C. van Beurden, "Electromagnetic embedding," in 29th URSI General Assembly, July 2005.

[3] D. Bekers, Finite Antenna Arrays, an eigencurrent approach. PhD thesis, Technische Universiteit Eindhoven, 2004. 